Journal of Applied Pharmaceutical Science Vol. 5 (09), pp. 106-109, September, 2015

Available online at http://www.japsonline.com

DOI: $10.7324 /$ JAPS.2015.50919

ISSN 2231-3354 (cc) BY-NC-SA

\title{
Pacing Indications and Modes in Bradyarrhythmia Patients: Gender Related Differences
}

\author{
Pratibha Singh ${ }^{1}$, Rohit Kumar Srivastava ${ }^{2}$, Rishi Sethi ${ }^{3}$, Wahid $\mathrm{Ali}^{1 *}$, Shankar Madhav Natu ${ }^{1}$, Sunita Tiwari ${ }^{2}$ \\ ${ }^{1}$ Department of Pathology, King George's Medical University, Lucknow, U.P., India. ${ }^{2}$ Department of Physiology, King George's Medical University, \\ Lucknow, U.P., India-226003. ${ }^{3}$ Department of Cardiology, King George's Medical University, Lucknow, U.P., India.
}

\author{
ARTICLE INFO \\ Article history: \\ Received on: 04/06/2015 \\ Revised on: 19/07/2015 \\ Accepted on: 12/08/2015 \\ Available online: 27/09/2015 \\ Key words: \\ Bradyarrhythmia; Pacemaker \\ implantation; Gender; Pacing \\ Indications; Pacing Modes. \\ Abbreviations: \\ SCD - Sudden Cardiac Death \\ CHB - Complete Heart Blockage \\ AV Block -Atrioventricular Block \\ SSS-Sick Sinus Syndrome
}

\begin{abstract}
Gender differences are increasingly recognized in cardiology. It is also well known that women have higher complications and a higher mortality related to coronary procedures. In arrhythmias, gender-specific variations in the electrophysiological structure of the heart or hormonal effects may explain some of the gender differences. The aim of this study was to evaluate gender differences according to their risk factors, indications and modes of pacing. A total of 267 patients who had pacemaker implantation for bradyarrhythmia indications were enrolled in our study. A pre-designed questionnaire was filled to record their baseline characteristics, clinical indications and mode of pacing. Out of 267 patients 190 were male and 77 were female. Data was analyzed with SPSS 16.0 software (SPSS, Chicago, IL, USA) The pacemaker implantation requirement was $31 \%$ significantly lower among males compared with females who were hypertensive $(R R=0.69,95 \% \mathrm{CI}=0.58-0.82, \mathrm{p}=0.0001)$ and 1.57 times $(\mathrm{RR}=1.57,95 \% \mathrm{CI}=1.32-1.87, \mathrm{p}=0.0001)$ significantly higher among male patients than females who were the tobacco user in any form. The single chamber requirement was 1.41 times significantly ( $R R=1.41$, 95\% CI=1.16-1.71, $\mathrm{p}=0.0001)$ higher in males than females. The risk analysis showed that complete heart blockage $(\mathrm{p}=0.02)$ and sick sinus syndrome $(\mathrm{p}=0.01)$ were significantly higher in males as compared with females. In conclusion male patients had more $\mathrm{CHB}$, sick sinus syndrome and syncope as primary pacemaker indication, compared with female patients. Smoking was the most prominent risk factor in male and hypertension in female and most importantly there were significant gender differences in indications leading to pacing.
\end{abstract}

\section{INTRODUCTION}

Cardiac arrhythmia encompasses a large and heterogeneous group of electrical abnormalities of the heart, with or without underlying structural heart disease. Cardiac arrhythmias can be innocuous, can predispose to the development of potentially lethal stroke or embolus, or can present emergently with a life-threatening condition that may result in sudden cardiac death (SCD), one of the most common causes of death in the developed countries (Tester and Ackerman, 2011) Arrhythmias resulting in bradycardia or tachycardia can be thought of as specific disorders of each of these components (Olgin and Zipes, 2011). Bradyarrhythmia is a general term that describes a number of conditions in which the heart beats at an unusually slow rate (fewer than 50 to 60 beats per minute). However, electrical impulses may be slowed, delayed, or blocked

\footnotetext{
* Corresponding Author

Dr. Wahid Ali, Department of Pathology King George's Medical University Lucknow, U.P., India.Email aliwahid78@gmail.com
}

altogether, resulting in bradyarrhythmia. This may be due to aging, medication, metabolic disturbances or pre-existing heart disease. Pacemaker implantation is performed for patients of all ages with bradyarrhythmias (Greenspon et al., 2012; Coma et al., 2010). Gender differences are increasingly recognized in cardiology, concerning coronary interventions (Jacobs, 2003) or arrhythmias (Beauregard, 2002). A recently published ICD study revealed significantly more implantation complications in women (Peterson et al., 2009). Data regarding gender effects onto pacemaker implantation are scanty. Therefore, the aim of this study was to evaluate whether gender differences play a role in pacemaker implantation and also compare the differences in their risk factors, complications, indications and modes of pacing.

\section{SUBJECTS AND METHODS}

\section{Subject selection}

The study was conducted in the pacemaker clinic in the Department of Cardiology, King George's Medical University, Lucknow. 
The study was carried out in accordance with the ethical standards of the university (Ethical Clearance Certificate No. 63ECM-IIB/2). The patients who were diagnosed with bradyarrhythmia and related conduction disorders and had permanent pacemaker implantation in situ were enrolled for the study. Inclusion criteria of the patients were- a) Subjects of both sexes above 18 years presenting with bradyarrhythmia and conduction disorder. b) Subjects of both sexes having pacemaker implanted previously for bradyarrhythmias. c) Subjects willing to give written informed consent. Exclusion criteria includeda) Subjects of both sexes below 18 years. b) Subjects of both sexes, not having indication of pacemaker implantation. c) Not willing to give written informed consent.

A detailed questionnaire was developed with the help of a physician in the institute. The questionnaire was filled with the help of physician to record sex, age, history of tobacco consumption, history of hypertension, diabetes, history of other complications and types of pacemaker implanted. Heart rate and blood pressure was also estimated at the time of the enrolment. Pacemaker details, complication rates and modes of pacing were also recorded. A written informed consent was obtained from every patient. Blood pressure was measured with the patients in a sitting position after a 5-minute rest with use of a mercury sphygmomanometer and read to the nearest $2 \mathrm{~mm} \mathrm{Hg}$. Subjects were classified as having hypertension if they were receiving drug treatment for hypertension or had systolic blood pressure of at least $160 \mathrm{~mm} \mathrm{Hg}$ or diastolic blood pressure of at least $95 \mathrm{~mm} \mathrm{Hg}$. Other cardiovascular risk factors like diabetes were defined as follows: if the patient was treated for diabetes or was previously diagnosed by a primary care physician according to guidelines.

Patients who were taking tobacco in any form (bidi, cigarette, khaini, gul, gutkha, hukka, pan etc.) were considered in the tobacco consumption category.

\section{Statistical analysis}

The SPSS software (Chicago, Illinois; Version 15.0) was used for all statistical analyses. A P-value of $<0.05$ was considered significant. Data are presented as percentages for discrete variables and as mean \pm standard deviation and/or median for continuous variables. Differences in baseline characteristics between age groups were compared using unpaired t-test and Fisher's exact test.

\section{RESULTS}

Out of the total 267 patients studied, there were 190 males and 77 females with previously implanted pacemaker. No significant difference $(p>0.05)$ in the age was found between male $(63.84 \pm 12.38)$ and female $(62.16 \pm 11.37)$ patients. Among hypertensive subjects, the pacemaker implantation requirement was $31 \%$ significantly lower among males as compared with females $(\mathrm{RR}=0.69,95 \% \mathrm{CI}=0.58-0.82, \mathrm{p}<0.001)$. However, there was no association between diabetes status and gender in the requirement of pacemaker ( $p>0.05$ ). Amongst those consuming tobacco in any form, pacemaker requirement was 1.57 times $(\mathrm{RR}=1.57,95 \% \mathrm{CI}=1.32-1.87, \mathrm{p}<0.001)$ significantly higher among male patients than females (Table-1).

The single chamber pacemaker requirement was $84.2 \%$ among males and $59.7 \%$ in females. However, dual chamber pacemaker requirement was $15.8 \%$ in males and $40.3 \%$ in females. The single chamber requirement was 1.41 times $(\mathrm{RR}=1.41,95 \%$ $\mathrm{CI}=1.16-1.71, \mathrm{p}<0.001)$ significantly higher in males than females (Table-2).

The percentage of CHB was higher among male (44.7\%) patients than female $(40.3 \%)$ patients. The risk analysis showed that $\mathrm{CHB}$ was 2.74 times significantly higher in males compared with females $(\mathrm{RR}=2.74,95 \% \mathrm{CI}=1.12-6.74, \mathrm{p}=0.02)$. SSS was 8 times higher among males than in females $(R R=8.00$, 95\% $\mathrm{CI}=1.50-42.65, \mathrm{p}=0.01)$ and this was statistically significant. The percentage of syncope was $6.8 \%$ in males and $3.9 \%$ in females, however, the difference was nearly significant $(\mathrm{p}=0.05)$. Other symptoms were not found to be associated $(p>0.05)$ with gender (Table-3).

Multivariate analysis revealed that hypertension ( $\mathrm{p}<0.001)$, smoking $(\mathrm{p}=0.001)$, pacing indications $(\mathrm{p}=0.001)$, SSS symptoms $(\mathrm{p}=0.003)$ and syncope were significantly associated with gender and the requirement of pacemaker (Table-4).

Table 1: Baseline characteristics of the patients with bradyarrhythmia and conduction disorder.

\begin{tabular}{|c|c|c|c|c|c|c|}
\hline \multirow[t]{2}{*}{ Baseline characteristics } & \multicolumn{2}{|c|}{$\begin{array}{c}\text { Male } \\
(n=190)\end{array}$} & \multicolumn{2}{|c|}{$\begin{array}{r}\text { Female } \\
(n=77)\end{array}$} & \multirow[t]{2}{*}{ RR (95\% CI), } & \multirow[t]{2}{*}{ p-value } \\
\hline & No. & $\%$ & No. & $\%$ & & \\
\hline Age in years, mean \pm SD & \multicolumn{2}{|c|}{$63.84 \pm 12.38$} & \multicolumn{2}{|c|}{$62.16 \pm 11.37$} & $0.30^{\mathrm{a}}$ & \\
\hline Hypertension & 70 & 36.8 & 52 & 67.5 & $0.69(0.58-0.82)$ & $<0.001 *$ \\
\hline Diabetes & 60 & 31.6 & 32 & 41.6 & 0.87 (0.73-1.04), & 0.12 \\
\hline Tobacco consumption & 122 & 64.2 & 20 & 26.0 & $1.57(1.32-1.87)$ & $<0.001^{*}$ \\
\hline
\end{tabular}

RR-Relative risk, CI-confidence interval, ${ }^{\mathrm{a}}$ Unpaired t-test, $*$ Significant.

Table 2: Pacing indications of the patients with bradyarrhythmia and conduction disorder according to gender.

\begin{tabular}{|c|c|c|c|c|c|c|}
\hline \multirow[t]{2}{*}{ Pacing } & \multicolumn{2}{|c|}{$\begin{array}{c}\text { Male } \\
(\mathrm{n}=190)\end{array}$} & \multicolumn{2}{|c|}{$\begin{array}{r}\text { Female } \\
(n=77)\end{array}$} & \multirow[t]{2}{*}{ RR $(95 \%$ CI $)$, } & \multirow[t]{2}{*}{ p-value ${ }^{1}$} \\
\hline & No. & $\%$ & No. & $\%$ & & \\
\hline Single chamber & 160 & 84.2 & 46 & 59.7 & \multirow{2}{*}{1.41 (1.16-1.71), } & \multirow{2}{*}{$<0.001^{*}$} \\
\hline Dual chamber & 30 & 15.8 & 31 & 40.3 & & \\
\hline
\end{tabular}

RR-Relative risk, CI-confidence interval, *Significant. 
Table 3: Primary pacing indications in bradyarrhythmia and conduction disorder patients.

\begin{tabular}{|c|c|c|c|c|c|c|}
\hline \multirow[t]{2}{*}{ Indications } & \multicolumn{2}{|c|}{$\begin{array}{c}\text { Male } \\
(n=190)\end{array}$} & \multicolumn{2}{|c|}{$\begin{array}{r}\text { Female } \\
(\mathbf{n}=77)\end{array}$} & \multirow[t]{2}{*}{ OR $(95 \%$ CI $)$, } & \multirow[t]{2}{*}{ p-value ${ }^{1}$} \\
\hline & No. & $\%$ & No. & $\%$ & & \\
\hline CHB & 85 & 44.7 & 31 & 40.3 & 2.74 (1.12-6.74), & $0.02 *$ \\
\hline $1^{0} \mathrm{AV}$ block & 9 & 4.7 & 4 & 5.2 & $2.25(0.54-9.34)$ & 0.26 \\
\hline $2^{0} \mathrm{AV}$ block & 13 & 6.8 & 9 & 11.7 & $1.44(0.45-4.64)$ & 0.53 \\
\hline $3^{0} \mathrm{AV}$ block & 10 & 5.3 & 4 & 5.2 & $2.50(0.61-10.22)$ & 0.20 \\
\hline SSS & 16 & 8.4 & 2 & 2.6 & $8.00(1.50-42.65)$ & $0.01 *$ \\
\hline Syncope & 13 & 6.8 & 3 & 3.9 & $4.33(0.97-19.20)$ & 0.05 \\
\hline Symptomic bifascicular block & 5 & 2.6 & 2 & 2.6 & $2.50(0.40-15.50)$ & 0.32 \\
\hline Atrial fibrillation & 19 & 10.0 & 8 & 10.4 & $2.37(0.75-7.50)$ & 0.14 \\
\hline Sclerodegenerative & 8 & 4.2 & 2 & 2.6 & $4.00(0.70-22.87)$ & 0.11 \\
\hline AMI & 12 & 6.3 & 12 & 15.6 & 1.00 (Ref.) & \\
\hline
\end{tabular}

${ }^{1}$ Derived from binary logistic regression, OR-Odds ratio, CI-confidence interval, Ref-Reference, *Significant

Table 4: Results of multivariate logistic regression assessing the significant factors associated with the requirement of pacemaker among the patients of bradyarrhythmia between males and females.

\begin{tabular}{|c|c|c|c|c|}
\hline \multirow{2}{*}{ Factors } & \multirow{2}{*}{ Adjusted OR } & \multicolumn{2}{|c|}{ 95.0\% C.I. for adjusted OR } & \multirow{2}{*}{ p-value } \\
\hline & & Lower & Upper & \\
\hline Hypertensive & 0.10 & 0.04 & 0.23 & $<0.001 *$ \\
\hline Smoking & 9.29 & 4.29 & 20.11 & $<0.001 *$ \\
\hline Pacing indication & 4.01 & 1.70 & 9.44 & $0.001 *$ \\
\hline \multicolumn{5}{|l|}{ Symptom } \\
\hline $\mathrm{CHB}$ & 3.16 & 0.80 & 12.52 & 0.102 \\
\hline $1^{0} \mathrm{AV}$ block & 2.50 & 0.44 & 14.36 & 0.303 \\
\hline $2^{0} \mathrm{AV}$ block & 0.85 & 0.17 & 4.26 & 0.841 \\
\hline $3^{0} \mathrm{AV}$ block & 1.51 & 0.25 & 8.95 & 0.651 \\
\hline SSS & 23.74 & 2.94 & 191.37 & $0.003 *$ \\
\hline Syncope & 10.07 & 1.52 & 66.84 & $0.017 *$ \\
\hline Symptomicbifascicular block & 1.32 & 0.13 & 13.40 & 0.816 \\
\hline Atrial fibrillation & 1.96 & 0.43 & 8.90 & 0.381 \\
\hline Sclerodegenerative & 5.93 & 0.60 & 58.84 & 0.129 \\
\hline AMI & 1.00 (Ref.) & & & \\
\hline
\end{tabular}

Absence of hypertension, smoking and dual chamber were considered as Reference, OR-Odds ratio, CI-confidence interval, Ref-Reference, *Significant

\section{DISCUSSION}

Our data showed significant differences in risk factors, complications and modes of pacing between both the genders. Primary complications leading to pacing in males had more CHB, syncope and sick sinus syndrome as compared to females. This distribution can also be found in the Swedish pacemaker registry as well (Swedish Pacemaker Register, 2009). According to age, women were significantly less likely to receive a dual- chamber device with an age of 80 years or above with an indication of either AV block or sick sinus syndrome (Batz and Irnich, 1995; Batz and Irnich,1997; Schuppel et al., 1998). In our study women were significantly less likely to receive a single pacing $(\mathrm{p}<0.001)$. This result is inconsistent with the study of Lamas et al., (1995), in which they showed that men received proportionally more dual chamber pacemaker than women, even after adjustment for demographic and clinical characteristics (Lamas et al., 1995). This result is different from our study in which women were significantly less likely to receive a single pacing. The value is significant in men ( $\mathrm{p}$ value $<0.001)$. Very scanty literature is found of such a study related to pacing in bradyarrhythmia and conduction disorder. Similar work has been done from the German Pacemaker registry in the early 1990s which showed that men received more pacemakers than women and that DDD and rateresponsive systems were used more frequently in men (Batz and Irnich, 1995; Batz and Irnich,1997; Schuppel et al., 1998).
These differences are more accentuated in low volume centers. On the contrary, no gender differences for pacemaker implantation have been documented in an Italian study (Boccia et al., 2005). A study from The Netherlands evaluating 33,564 patients demonstrated no gender differences in pacemaker selection, but a considerable drop in dual-chamber implantation with increasing age (Roeters et al., 2000). Another single centre study evaluating 259 patients found no significant difference in pacemaker mode selection between male and female patients (Veerareddy et al., 2007). However, in this study, the patient group was considerably younger with a mean age of 61 years, when compared with our patient cohort with a mean age of 62 years. In our study smoking has emerged as one of the major risk factors for pacemaker patients in both the groups. We found that it causes adverse effect on the cardiac conduction system. It has been proved that consuming tobacco in any form (smoke and smokeless tobacco) cause adverse effect on health including cancer of oral cavity, oral soft tissue lesion, gum recession and nicotine addiction (Ferrence et al.., 2000; Hatsukami and Severson, 1999; Hatsukami et al.., 2004; Winn et al.., 1981) but in one study there was association between smokeless tobacco use and cardiovascular disease (Bolinder et al., 1994) although this has not been a consistent finding (Accortt et al.., 2002; Asplund, 2003). The adverse effects of smoking on vascular function have been examined in human subjects. These studies have shown that acute and chronic cigarette smoking impairs nitric oxide synthase 
mediated relaxation of large blood vessels (Zeiher et al., 1995; Silvestrini et al., 1996; Heitzer et al., 1996). However, a consensus of the causal relationship between electro physical disorders of the heart and consumption of smoking and smokeless tobacco has not yet been reached. What has been known is the acute hypertensive effect observed in smokeless tobacco users (Westman, 1995).

\section{CONCLUSION}

The present study concludes that there were significant gender differences in indications leading to pacing. Concerning complications leading to pacing in both the sexes, male patients had more $\mathrm{CHB}$, sick sinus syndrome and syncope as primary pacemaker indication, compared with female patients. Primary complications leading to pacing in males had more $\mathrm{CHB}$, syncope and sick sinus syndrome as compared to females. This distribution can also be found in the Swedish pacemaker registry as well. Also smoking emerged as the most prominent risk factor in male and hypertension in female.

\section{ACKNOWLEDGEMENT}

The authors express sincere thanks to the Council of Scientific and Industrial Research (CSIR), New Delhi for financial support to Pratibha Singh as Senior Research Fellow. (CSIR Sanction No. 09/910 (0009)/2010-EMR-I).

\section{REFERENCES}

Accortt NA, Waterbor JW, Beall C, Howard G. Chronic disease mortality in a cohort of smokeless tobacco users. Am J Epidemiol, 2002; 156:730-737.

Asplund K. Smokeless tobacco and cardiovascular disease. ProgCardiovasc Dis, 2003; 45:383-394.

Batz L, Irnich W. Demographische Aspekte der Schrittmachertherapie. Herzschr Elektrophys, 1995; 6:4-10.

Batz L, Irnich W. Gibtesgeschlechtsspezifische Unterschiede in der Schrittmacherauswahl? BiomedizinischeTechnik, 1997; 42:77-8.

Beauregard LA. Incidence and management of arrhythmias in women. J GendSpecif Med, 2002; 5:38-48.

Boccia A, Damiani G, D’Errico MM, Farinaro E, Gregorio P, Nante $\mathrm{N}$ et al. Ageand sex-related utilisation of cardiac procedures and interventions: a multicentric study in Italy. Int J Cardiol, 2005;101:179-84.

Bolinder G, Alfredsson L, Englund A, de Faire U. Smokeless tobacco use and increased cardiovascular mortality among Swedish construction workers. Am J Public Health, 1994; 84:399-404.

Coma Samartin R, Sancho-Tello de Carranza MJ, Ruiz Mateas F, Leal del Ojo González J, Fidalgo Andrés ML; Sección de Estimulación Cardiaca. Sección de EstimulaciónCardiaca. Spanish pacemaker registry. Eighth official report of the Spanish Society of Cardiology Working Group on Cardiac Pacing. Rev EspCardiol, 2011; 64 (12):1154-1167.

Ferrence R, Slade J, Room R, Pope M, eds. Nicotine and Public Health. Washington, DC: American Public Health Association; 2000.
Greenspon AJ, Patel JD, Lau E, Ochoa JA, Frisch DR, Ho RT et al. Trends in permanent pacemaker implantation in the United States from 1993 to 2009: increasing complexity of patients and procedures. J Am Coll Cardiol, 2012; 60 (16):1540-1545

Hatsukami DK, Lemmonds C, Tomar SL. Smokeless tobacco use: harm reduction or induction approach? Prev Med, 2004; 38:309-317.

Hatsukami DK, Severson HH. Oral spit tobacco: addiction, prevention and treatment. Nicotine Tob Res, 1999; 1:21-44.

Heitzer T, Just H, Munzel T. Antioxidant vitamin C improves endothelial dysfunction in chronic smokers. Circulation, 1996; 94:6-9.

Jacobs AK. Coronary revascularization in women in 2003: sex revisted. Circulation, 2003; 107:375-7.

Lamas GA, Pashos CL, Normand SLT, McNeil B. Permanent pacemaker selection and subsequent survival in elderly medicare pacemaker recipients. Circulation, 1995; 91:1063-1069.

Olgin J, Zipes DP. 2011. Specific Arrhythmias: Diagnosis and treatment.Braunwald's Heart disease. A textbook of Cardiovascular Medicine. $9^{\text {th }}$ Edition. pp771-824.

Peterson PN, Daugherty SL, Wang Y, Vidaillet HJ, Heidenreich PA, Curtis JP et al. Gender differences in procedure-related adverse events in patients receiving implantable cardioverter-defibrillator therapy. Circulation, 2009; 119:1078-84.

RoetersvanLennep JE, Zwinderman AH, Roeters van Lennep HWO, van Hemel NM, Schalij MJ, van der Wall EE. No gender differences in pacemaker selection in patients undergoing their first implantation. PACE, 2000; 23:1232-8.

Schuppel R, Buchele G, Batz L, Koenig W. Sex differences in selection of pacemakers:retrospective observational study. BMJ, 1998; 316:1492-5.

Silvestrini M, Troisi E, Matteis M, Cupini LM, Bernardi G. Effect of smoking on cerebrovascular reactivity. J. Cereb. Blood Flow Metab, 1996; 16:746-749.

Swedish Pacemaker Register. Annual Statistical Report 2007. http://www.Pacemakerregistret.se/icdpmr/annualReport/2007/annual Report_2007.pdf (last accessed 14 October 2009).

Tester DJ, Ackerman MJ. Genetics of cardiac arrhythmias. Braunwald's Heart disease. A textbook of Cardiovascular Medicine. $9^{\text {th }}$ Edition. 2011; pp81-90.

Veerareddy S, Arora N, Caldito G, Reddy PC. Gender differences in selection of pacemakers: a single center study. Gend Med, 2007; 4:367-73.

Westman EC. Does smokeless tobacco cause hypertension? South Med J, 1995; 88:716- 720.

Winn DM, Blot WJ, Shy CM, Pickle LW, Toledo A, Fraumeni JF Jr. Snuff dipping and oral cancer among women in the southern United States. New Engl J Med, 1981; 304:745-749.

Zeiher AM, Schachinger V, Minners J. Long-term cigarette smoking impairs endothelium-dependent coronary arterial vasodilator function. Circulation, 1995; 92: 1094-1100.

\section{How to cite this article:}

Pratibha Singh, Rohit Kumar Srivastava, Rishi Sethi, Wahid Ali, Shankar Madhav Natu, Sunita Tiwari. Pacing Indications and Modes in Bradyarrhythmia Patients: Gender Related Differences. J App Pharm Sci, 2015; 5 (09): 106-109. 